\title{
Assessment of Parshall flumes for discharge measurement of open-channel flows: A comparative numerical and field case study
}

\author{
Ali Khosronejad ${ }^{\mathrm{a}, *}$, William Herb ${ }^{\mathrm{b}}$, Fotis Sotiropoulos ${ }^{\mathrm{a}}$, Seokkoo Kang ${ }^{\mathrm{c}}$, Xiaolei Yang ${ }^{\mathrm{d}}$ \\ ${ }^{a}$ Civil Engineering Department, Stony Brook University, Stony Brook, NY, USA \\ ${ }^{\mathrm{b}}$ St. Anthony Falls Laboratory, University of Minnesota, Minneapolis, MN, USA \\ ${ }^{\mathrm{c}}$ Civil and Environmental Engineering Department, Hanyang University, Seoul, Republic of Korea \\ ${ }^{\mathrm{d}}$ The State Key Laboratory of Nonlinear Mechanics, Institute of Mechanics, Chinese Academy of Sciences, Beijing, China
}

\section{A R T I C L E I N F O}

\section{Keywords:}

Parshall flume

Flow discharge

Large-eddy simulation

Level set method

Dye dilution experiment

\begin{abstract}
A B S T R A C T
This paper presents a series of numerical and field studies to examine the accuracy of two field-scale Parshall flumes, which are employed to measure the flow rate of a wastewater system in the city of Minneapolis, Minnesota. The numerical studies were carried out using the large-eddy simulation (LES) and level-set methods to compute the turbulent flow of sewers under two-phase flow (wastewater and air) conditions. Flow rate measurements in the field were conducted using the dye dilution approach and an in-site flow measuring tool. Using the combination of field measurements and numerical simulations, this research aims at quantifying (i) the margin of error of the filed-scale Parshall flumes and (ii) the water surface fluctuations within the Parshall flumes. The LES turbulent model, coupled with the level-set method, allowed for resolution of instantaneous water surface variations and uncertainty quantification of the flow rate measurements.
\end{abstract}

\section{Introduction}

The Parshall flume was originally developed in the 1920s, as a means for measuring irrigation water flows in open channels [1]. The Parshall flume design includes a contraction of both sidewalls and a drop in the floor at the flume throat (see Fig. 1). Initially, data from Parshall flumes with throat widths of $0.15 \mathrm{~m}, 0.30 \mathrm{~m}, 0.61 \mathrm{~m}, 0.91 \mathrm{~m}, 1.22 \mathrm{~m}, 1.83 \mathrm{~m}$, and $2.44 \mathrm{~m}$ were obtained in a field laboratory in Colorado, USA [2], in which the testing included both free and submerged outflow conditions. The derived formula relating the stage to flow rate in the free-flow condition was developed using a total of 298 measurements in flumes ranging from $0.15 \mathrm{~m}$ to $2.44 \mathrm{~m}$ throat widths, including 34 measurements in a $0.91 \mathrm{~m}$ flume and 21 tests in a $1.22 \mathrm{~m}$ flume [2]. The distribution of error between the empirical formula and the flow-stage observations ranged from $-7 \%$ to $11 \%$, with the vast majority of error values within $\pm 3 \%$ [2]. For the free outflow conditions in $0.3 \mathrm{~m}$ to 2.44 $\mathrm{m}$ Parshall flumes, the flow rate $\left(\mathrm{Q}\left(\mathrm{m}^{3} / \mathrm{s}\right)\right)$ depends only on the upstream water level, $\mathrm{H}_{\mathrm{a}}(\mathrm{m})$, and the throat width of the flume, $\mathrm{W}(\mathrm{m})$, as follows $[2,3]$ :

$Q=4 W H_{a}^{1.522 W^{0.026}}$
More complex flow and water level relationships for the submerged flow are also available (see, e.g., [4]). Numerous studies have tested the accuracy of the original Parshall flume rating curve (Eq. (1)) and quantified the effects of inlet conditions, dimensional and leveling errors, and level measurement errors on the accuracy of Parshall flumes for flow rate measurements. Using data from Parshall flumes of up to $4.57 \mathrm{~m}$ throat width installed in an experimental watershed, Blaisdell [5] found the original Parshall flume equations to be accurate within $\pm 5 \%$. Chen et al. [6] tested $0.22 \mathrm{~m}$ and $0.46 \mathrm{~m}$ wide Parshall flumes with varying transition lengths from a circular, upstream supply pipe to the flume throat. Substantial over-predictions of flow rates were found between the observed stage-discharge data and Parshall flume's standard relationship, including errors of up to $50 \%$ at low flows. The discrepancies were found to depend both on the length of the upstream transition and the slope of the supply pipe.

A survey of 50 installed Parshall flumes in Utah found only approximately half of them to be within the rated accuracy $( \pm 5 \%)[7]$. Common issues identified at the field sites included incorrect entrance geometry and incorrect staff gauge locations. Corrections to the Parshall flume stage-discharge relationships have been developed to consider lateral or longitudinal settling of the flume $[8,9]$. Lateral settling (tilting) of $\pm 2 \%$ gave flow measurement errors of $3 \%$ to $11 \%$, depending on

\footnotetext{
* Corresponding author.

E-mail address: ali.khosronejad@stonybrook.edu (A. Khosronejad).
} 


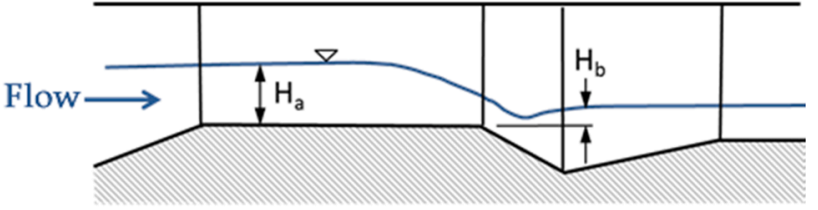

(a)

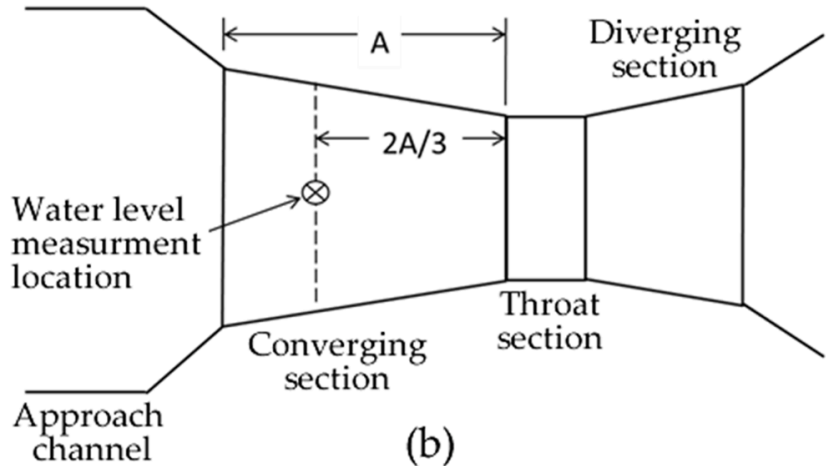

Fig. 1. Schematic of the water level measurement location from the side (a) and top (b) views to find Ha. The location of the water level measurement is shown at a distance $2 \mathrm{~A} / 3$ upstream of the throat section, where $\mathrm{A}$ is the length of the converging section. We note that in a standard Parshall flume, the flow depth $\mathrm{Ha}$ is normally measured at $2 \mathrm{~A} / 3$ along the side walls using a static head gauge. In this test case, however, the flow depths are measured using sonar equipment, installed over the top of the sidewalls, which reads the water depth at the center of the flume, as seen in (b). Flow is from left to right.

the level of flow submergence.

Experimental and numerical studies of the accuracy of Parshall flumes at low flows found significant discrepancies for flows below $15 \%$ of the maximum flow rate $[10,11]$. The discrepancies were found to be as high as $25 \%$ for flumes with throat widths ranging from $0.076 \mathrm{~m}$ to $0.61 \mathrm{~m}$. Alternative rating equations for low flows are given in the same form as Eq. (1). Dahlin and Wetzel [12] quantified the effect of non-ideal entrance conditions on the accuracy of Parshall flumes. Their measurements were performed on a $0.30 \mathrm{~m}$ Parshall flume using weighing tanks as an independent and calibrated flow measurement. Tests included a standard installation based on recommended installation practices, trapezoidal and circular supply channels, different wing-wall configurations, partial blockages, and lateral offsets between the flume and supply channel. For the standard installation, the flow-stage data points were close to the standard curve at high flows, but higher deviations were found at low flows. Deviation of the measured discharge from the standard curve varied from approximately $1.2 \%$ at the higher flows to 10 to $15 \%$ at low flows. Introducing lateral offsets to the inflow produces additional variations in the rating curve, with deviations of up to $20 \%$ from the standard curve at low flows.

Several studies have employed computational fluid dynamics (CFD) models to examine the performance of Parshall flumes. A previous study conducted by Wright et al. [11] included a one-dimensional (1D) numerical model. Davis and Deutsch [13] developed an inviscid threedimensional finite-difference model to simulate the flow in the entrance section of Parshall flumes and compared it to experimental data from a $0.15 \mathrm{~m}$ Parshall flume. They used the Reynolds-Averaged Navier-Stokes (RANS) modeling approach to resolve the flow field. For water depths greater than approximately $0.18 \mathrm{~m}$, the numerical model over-predicted the discharge by approximately $5 \%$. Savage et al. [14] used the RANS - based module of the FLOW-3D model to simulate correction coefficients for Parshall flumes. The correction coefficients were determined to compensate for incorrectly located staff gages. A computational grid system, including approximately 0.2 million grid cells, was used. Comparisons of their CFD simulation results to experimental data for a $0.61 \mathrm{~m}$ flume showed agreement within 0.01 to $0.02 \mathrm{~m}$ of the water depth (head), depending on the configuration, representing an accuracy within $5 \%$ for $90 \%$ of the measurements. Rating curve deviations of up to $5 \%$ were found between cases with and without wing walls, and deviations of up to $60 \%$ for incorrectly located staff gages. Temeepattanapongsa et al. [29] and Ran et al. [30] employed RANS based module of the Flow-3D to investigate water depth and flow rate rating curves of various Cutthroat flumes. Among others, Hirt and Williams [31], Kim [32], Willeitner [33], Heiner and Barfuss [34] also used CFD models that to assess the performance of flow control and measurement devices such as Parshall flumes.

This study seeks to utilize the (1) dye dilution approach, (2) rating curves based on the water surface elevation readings of sonar device, (3) temporary flow meter, and (4) CFD based model to investigate the turbulent free-surface flow of the Minneapolis Met council's Side A and B Parshall flume metering station over a range of flows. The main objectives of this study are twofold. First, it aims to quantify deviations of the actual Side A and B flumes' rating curves from the standard Parshall flume rating curves [1]. And, therefore, to find out whether any corrections (for the coefficients of the existing rating curve) are required to amend the existing rating curves of the Parshall flumes. Secondly, we are interested in using a numerical modeling approach to study the magnitude of the instantaneous water surface fluctuations in the Parshall flume. Additionally, in this aim, we interested to see whether altering the design of the flumes can enhance the accuracy of the flow rate readings. We note that water surface fluctuations in the Parshall flumes could impact the accuracy of the water-depth readings in the flume and, consequently, the measured flow rate of the system. Therefore, it is imperative to reduce the water surface fluctuations in the system. As a practical approach, a step baffled was previously installed in Side B flume. By altering the original design of the Side B flume's bed, the flume operators intended to lower the water surface fluctuations. Conducting a series of numerical simulations, we modeled the Side B flume with and without the step baffle to examine its impact on the water surface fluctuations and flow-rate measurements.

Since we are interested in capturing the fluctuations of the water surface, it is essential to use a turbulent modeling approach that is not as diffusive as RANS - based model and can simulate the large-scale flow structures that induce free surface fluctuations [19]. For that reason, and despite the great success and capability of RANS-based models, herein, we employ the large-eddy simulation (LES) method to resolve the turbulent free-surface flow. The originality of the current work pertains to combining various measuring techniques and numerical simulations to evaluate the accuracy of Parshall flumes. Plus, to our knowledge, this is the first attempt to use LES to resolve the turbulent free-surface flow of Parshall flumes and to track the instantaneous deformations of the water surface by coupling LES with the level set method $[20,21]$.

A schematic of the Side A and B Parshall flume metering station is shown in Fig. 2. The incoming flow is split into two parallel channels, with the A-side passing through a $0.91 \mathrm{~m}$ Parshall flume and the B side passing through a $1.22 \mathrm{~m}$ Parshall flume. In this work, we investigate the accuracy of flow rate measurements of both Side A and B flumes of the metering station.

\section{Materials and methods}

\subsection{Dye dilution method for field measurements of flow rate}

The dye dilution method for flow rate measurement uses Rhodamine WT as the tracer, injected upstream of the Side A and Side B flume sites (Fig. 2); which are located at geographic coordinate of $44.9778^{\circ} \mathrm{N}$, $93.2650^{\circ} \mathrm{W}$; at a rate of approximately $20 \mathrm{ml} / \mathrm{min}$, using a Fluid Metering Inc. (FMI) synchronous metering pump. The permission required to conduct the field test was provided by Eugene Vialrs of the Minneapolis Metropolitan Council. The dye was supplied from a 1-liter graduated glass burette, allowing the dye injection rate to be independently measured over the $1 \mathrm{~h}$ injection time. During each test, the times 


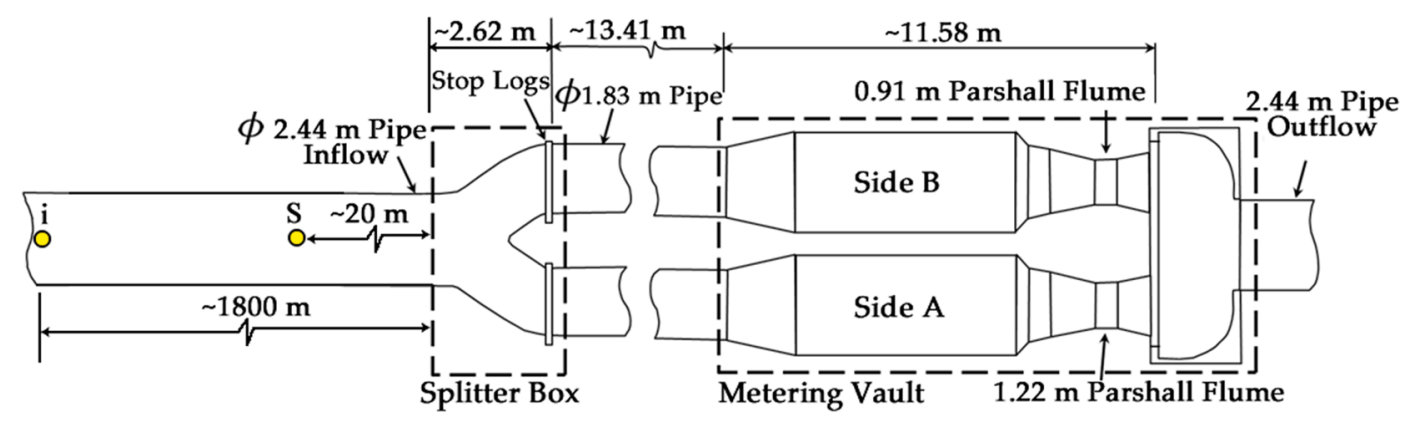

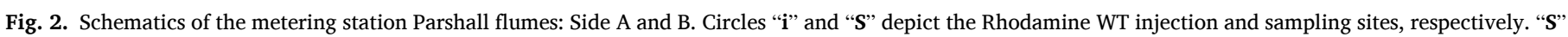
is where the utility hole MH-8A is located. Flow is from left to right.

were recorded for the dye supply to reach each 50 to $100 \mathrm{ml}$ increment in the burette. Depending on the expected flow rate, the Rhodamine WT was diluted 1:1 to $1: 3$ with water. All the sampling was carried out at the utility hole MH-8A located immediately upstream of the Side A and B flume sites. Samples of $4 \mathrm{ml}$ were taken from the $2.44 \mathrm{~m}$ pipe (see Fig. 2) at $1 \mathrm{~min}$ intervals over $1 \mathrm{~h}$. A larger sample of the wastewater was also taken before dye injection, for controlled dilution of the samples. To minimize the degradation of the dye, the samples were refrigerated for testing in the laboratory.

Sample testing in the laboratory consisted of both testing the field samples and making controlled dilutions of the dye samples to obtain a fluorescence - dilution calibration curve for each measurement. The procedures used were similar to those described by Morgan et al. [15]. Sub-samples of the $4 \mathrm{ml}$ field samples were filtered into the fluorometer cuvettes, using glass wool to remove large particles. The cuvettes were placed in a water bath for at least $30 \mathrm{~min}$ to equilibrate the sample temperatures. The fluorescence of the samples was then measured in a Turner Model 10 fluorometer. The tested samples included sewer samples, taken prior to dye injection, and samples taken during dye injection. Controlled dilutions of the injection dye stock were made using volumetric flasks and an Eppendorf automatic pipette.

Each sample required a series of 4 dilutions, with the last two dilutions made using sewer blank samples. Each dilution set had 1 dilution (X) that targeted the sample dilution (based on the estimated flow rate), plus $0.5 \mathrm{X}$ and $2 \mathrm{X}$ dilutions to bracket the targeted dilution. At least two replicates were prepared to demonstrate the repeatability of the dilutions. The fluorescence of the controlled dilution samples was then tested in the same manner as that of the field samples. For both the field samples and the controlled dilution samples, the sample fluorescence was measured as soon as possible after the samples were taken, and again after approximately $24 \mathrm{~h}$. Even with refrigeration, degradation of fluorescence over time was observed in both the field samples and the controlled dilution samples.

For this reason, an effort was made to test the fluorescence of the field samples and the controlled dilution samples for a similar time period after mixing. For example, if the field samples were tested $4 \mathrm{~h}$ after dye injection, the controlled dilution samples were tested $4 \mathrm{~h}$ after preparation. The flow rate was calculated from the fluorescence measurements as follows. Based on the controlled dilutions, a curve was established (linear slope and intercept) for each measurement set to relate fluorescence $(f)$ to dye dilution $(D)$.

$D=a\left(f-f_{o}\right)+b$

where $a$ and $b$ are the slope and intercept of the fluorescence-dilution curve, respectively, and $f_{o}$ is the fluorescence of the sewer blank (wastewater prior to dye injection). The wastewater flow rate $(Q)$ was then calculated as

$Q=q \cdot D$

where $q$ is the dye injection rate.

\subsection{Other flow rate measuring devices}

Flow rate measurements were carried out using the standard rating curves based on the water surface elevation readings of a passive sonar system (SONARtrac VF-50) installed over the sidewalls of the flumes (see Fig. 1(b)). The sound waves radiated from the sonar enter into the flowing water along vertical and get reflected from the bottom of the flume. The sonar system is calibrated such that the travel time of the sound wave is used to find the distance of the sonar from the water surface. In doing so, we are able to measure instantaneous water depth with an accuracy of $\pm 0.1 \mathrm{~mm}$.

The other flow meter that was employed in this study includes a temporary flow meter (ISCO Pro-20 Area-Velocity meter) that uses acoustic Doppler effect to measure the flow rate of the Parshall flumes in Side A and B. The temporary flow meter is a velocity profiler designed for high accuracy flow measurements in pipes with shallow water depth. We employed the device in the $\varnothing 1.83 \mathrm{~m}$ pipes upstream of the Side A and B flume (see Fig. 2) to measure the velocity profile and, consequently, the flow discharge.

\subsection{Numerical model for flow rate prediction}

\subsubsection{Numerical model}

The numerical model, which includes our in-house and open-source Virtual Flow Simulator (VFS-Geophysics) code [27], solves the spatially filtered incompressible Navier-Stokes and continuity equations for two immiscible fluids by the LES method. The sub-grid stress terms in the momentum equations are modeled using the constant Smagorinsky SGS model with a constant coefficient of $0.027[16,27]$. The threedimensional (3D) evolution of the water/air interface is modeled by the level-set method, which solves the spatially filtered advection equation of the level-set function for quantifying the location of the free surface [17].

The governing equations are discretized in space on a hybrid staggered/non-staggered grid arrangement using second-order accurate central differencing for the convective terms along with second-order accurate, three-point central differencing for the divergence, pressure gradient, and viscous-like terms. The time derivatives are discretized using a second-order backward differencing scheme [18]. The discrete flow equations are integrated in time using an efficient, second-order accurate fractional step methodology coupled with a Jacobian-free, Newton-Krylov solver for the momentum equations and the generalized minimal residual method (GMRES) solver enhanced with the multigrid method as a preconditioner for the Poisson equation. For additional details, the reader can refer to Khosronejad and Sotiropoulos [19]. The level-set equation for the water/air interface motion is discretized in space by the third-order weighted essentially non-Oscillatory (WENO) scheme [20]. The second-order essentially non-oscillatory (ENO) scheme proposed by Sussman et al. [21] is employed to discretize the gradient term in the mass conserving reinitialization.

To simulate the flow within the complex-shape channels and 
conduits, the model employs the curvilinear immersed boundary (CURVIB) method. In this approach, the flow domain was discretized with the Cartesian grid system. The computational nodes are classified into three categories: fluid, immersed boundary (IB), and solid nodes. According to the CURVIB method, the governing equations are solved at the background grid nodes placed within the fluid (fluid nodes) with boundary conditions identified at the fluid nodes that are in the immediate vicinity of the immersed boundary (IB nodes) (Fig. 3). All nodes inside the solid volumes (solid nodes) are blanked out from computations [22-24]. The CURVIB method has been successfully validated and applied to simulate a wide range of complex open-channel flows [17,22-27]. Finally, the VFS-Geophysics model takes advantage of massively parallel computing clusters [28].

\subsubsection{Flow rate computations using the numerical model}

The 3D geometry of the Side A and B metering station was measured with a laser scanner and used to generate the computational model of the flume (Fig. 4). Although both flumes are flatbed and had standard dimensions, slight imperfections and asymmetries were present in the laser scan geometry, which was maintained in the computational mesh. The computational grid systems for the flow field and water surface simulations of Side A and B flumes contain approximately 6.5 (i.e., 801 $\times 101 \times 81$ nodes in streamwise, spanwise, and vertical directions, respectively) and 8.7 million computational nodes (i.e., $801 \times 133 \times 81$ nodes in streamwise, spanwise, and vertical directions, respectively), respectively, with an average resolution of approximately $0.02 \mathrm{~m}$. The computational grid systems for both Side A and B are uniformly distributed in all directions. The temporal step of the computations is $0.001 \mathrm{~s}$ to obtain a Courant-Friedrichs-Lewy (CFL) number equal to or smaller than 0.1 - ensuring numerical stability of the model for the twophase flow computations.

As seen in Table 1, the numerical simulations for Side A and B flumes were carried out using four and five different flow discharges, as the inlet flux, respectively. The discharges were selected such that they represent the rage of the flow rates $\left(0.5 \leq Q\left(m^{3} / s\right) \leq 2.0\right)$, which were observed during the operation of the Parshall flumes. As the flows in all cases were subcritical, the critical water surface elevation at the downstream section of each flume was set as the outlet boundary condition for the water depth to model the $1.22 \mathrm{~m}$ drop at the exit of the Side A and B flumes. The critical water depth, for each case, can be calculated using the explicit formula of critical depth as a function of channel geometry and flow discharge. For the inlet boundary condition, the flow

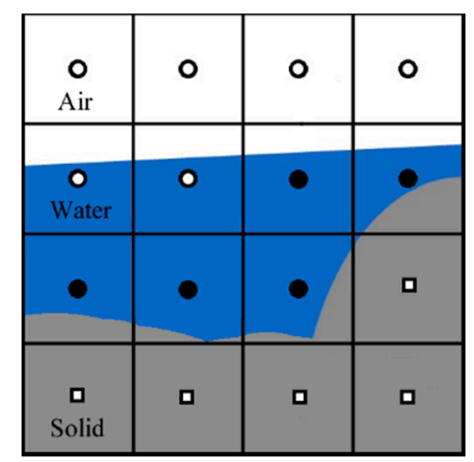

Fig. 3. Schematics of a computational domain with air (white), water (blue), and solid (gray) phases in the context of the immersed boundary (IB) method. Gridlines depict the background mesh. The free surface is marked with the interface of the water and air. The interface of water and solid is discretized with triangular mesh. Computational nodes that are located next to the solid and sediment surfaces are categorized as the IB nodes (bold circles), where the velocity field is reconstructed using the wall function. The nodes inside solid surfaces are categorized as solid nodes (hollow squares) and are blacked out of the computations, while the equations of fluid motion are solved at the fluid nodes (hollow circles). discharge was set (Table 1), and logarithmic velocity profiles were used to prescribe the velocity components. We employed a wall model to reconstruct the velocity components near the solid surfaces [19]. All simulations were continued until a quasi-steady-state condition was reached for the water surface elevation near the inlet. Finally, for each test case, 32 cores of a super-computing cluster $(2.8 \mathrm{GHz})$ were used to conduct the simulations. The simulations were continued for about 5 days (from 3 to 7 days) to complete.

\section{Results}

In this section, the measured and computed results of the flow rate predictions for the Side A and B Parshall flumes are presented and compared.

\subsection{Flow rate measurements in the field}

The dye dilution flow rate measurements were conducted at the Side $\mathrm{A}$ and $\mathrm{B}$ sites to obtain independent flow measurements for comparison against the model simulation results and the standard rating curve. Five measurements were carried out to obtain a range of low to high flow rate measurements on each of the two flumes, Side A and B flumes (Table 2). The flow rates were calculated from Eq. (3) for each sample to obtain the time variation of the calculated flow rate over each measurement interval. Throughout the course of the field measurements, it was noted that the time-averaged flow rate data over the one-hour measurement interval are the most reliable results. This is because the time-averaged data have reduced noise levels, which is caused by incomplete dye mixing that can lead to unrealistic fluctuations.

Flow rate measurements were also carried out using (a) the standard rating curves (based on the water surface elevation readings of the sonar system) and (b) the temporary flow meter. The time-averaged flow rates obtained from the standard rating curves and temporary flow meters were also associated with the least amount of the noise level owing to the rapid changes in water surface elevation and turbulent eddies that can lead to flow rate fluctuations. Examples of the instantaneously measured flow rate data in the Side B flume are shown in Fig. 5. In Table 3, the time-averaged flow rates obtained from the dye dilutions and the standard rating curve in both Side A and B flumes are compared.

\subsection{Numerical simulations of side A flume}

Simulations for this flume were carried out under four flow rates of $0.5,0.7,1.0$, and $1.5 \mathrm{~m}^{3} / \mathrm{s}$. All simulations were conducted with the computational grid system that contained approximately 6.5 million nodes. However, this case was also simulated with a coarser (with 1.9 million grid nodes) and a finer grid system (with 22 million grid nodes) to examine the grid sensitivity of the simulation results (Table 4) for the flow rate of $1.0 \mathrm{~m}^{3} / \mathrm{s}$. As seen in this table, the simulation results for the flow depth, Ha, using the 6.5 and 22 million grid nodes are converged. More specifically, the simulated average flow depth with 6.5 million nodes is less than $1 \%$ different from the result with 22 million nodes, whereas the coarser grid ( 1.9 million nodes) is $12 \%$ different. Thus, the grid system with 6.5 million grid nodes was utilized to conduct the simulations in the rest of this paper.

Fig. 6 demonstrates the simulation results of the instantaneous water elevation geometry and velocity magnitude for the flow discharges of $1.5 \mathrm{~m}^{3} / \mathrm{s}$. The simulation results for each case were time-averaged to obtain a time-averaged water surface elevation at the standard level measurement location of the Parshall flume. As seen in Fig. 1, this point is at the standard " $2 \mathrm{~A} / 3$ " location in the converging section, where an ultrasonic transducer reads the water surface elevation (centroid of the Parshall flume) instantaneously. The computed water depths are summarized in Table 5. Furthermore, the numerical simulation results for the case with the splitter (Fig. 7) agree closely with the result obtained with the standard geometry (without splitter). 

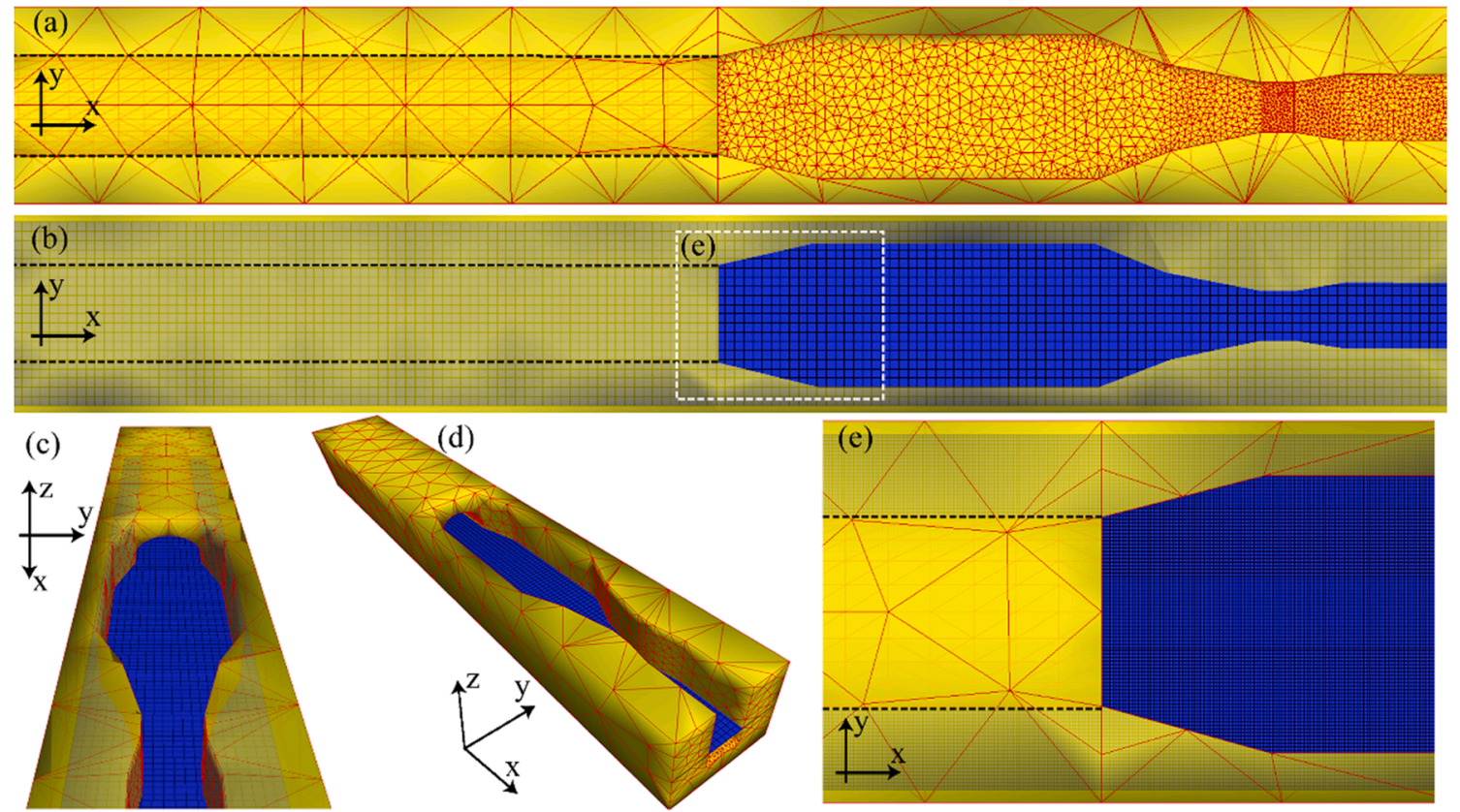

(d)

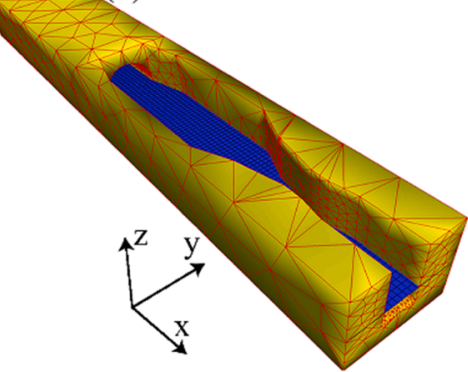

(e)

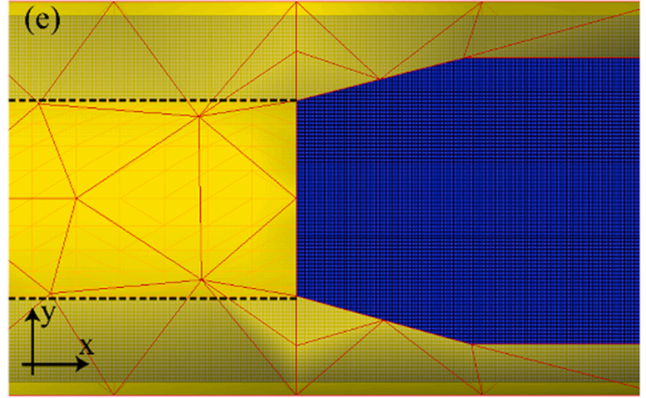

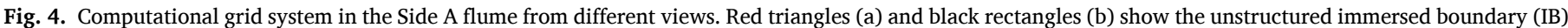

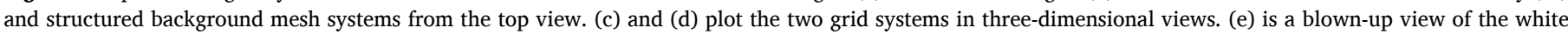

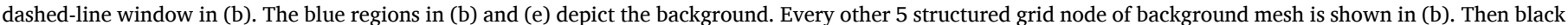
dashed lines in (a), (b), and (d) represent the location of the pipe upstream of the Parshall flume. Flow is along the x-axis.

Table 1

Flow rates $\mathrm{Q}\left(\mathrm{m}^{3} / \mathrm{s}\right)$ considered as the inlet flux for the numerical simulation of Side A and B flumes.

\begin{tabular}{ll}
\hline $\mathrm{Q}\left(\mathrm{m}^{3} / \mathrm{s}\right)$ & \\
Side A flume & Side B flume \\
\hline 0.5 & 0.5 \\
0.7 & 0.7 \\
1.0 & 1.0 \\
1.5 & 1.5 \\
- & 2.0 \\
\hline
\end{tabular}

Table 2

Summary of the five flow rate measurements using the dye dilution method.

\begin{tabular}{llllll}
\hline $\begin{array}{l}\text { Test } \\
\#\end{array}$ & $\begin{array}{l}\text { Day/ } \\
\text { Time }\end{array}$ & Flume & $\begin{array}{l}\text { Nominal Flow Rate } \\
\left(\mathrm{m}^{3} / \mathrm{s}\right)\end{array}$ & $\begin{array}{l}\text { Dye Injection } \\
\text { Site }\end{array}$ & $\begin{array}{l}\text { Sampling } \\
\text { Site }\end{array}$ \\
\hline 1 & $\begin{array}{l}18: 30 \\
\text { am }\end{array}$ & Side B & 1.11 .61 .11 .61 .1 & MH 1B & MH 8A \\
2 & $\begin{array}{l}24: 30 \\
\text { pm }\end{array}$ & Side B & & MH 7B & MH 8A \\
3 & $\begin{array}{l}38: 30 \\
\text { am }\end{array}$ & Side B & MH 7B & MH 8A \\
4 & $\begin{array}{l}45: 30 \\
\text { pm }\end{array}$ & Side A & MH 7B & MH 8A \\
5 & $\begin{array}{l}58: 50 \\
\text { am }\end{array}$ & Side A & MH 7B & MH 8A \\
\hline
\end{tabular}

\subsection{Numerical simulations of side B flume}

Figs. 8-12 illustrate the simulation results of the instantaneous water elevation geometry and velocity magnitude for various flow discharges in the Side B flume with a baffle step installed in the approach channel. As shown in these figures, the presence of the step baffle leads to backwater, which extends to the upstream closed conduit. As shown in the figures, depending on the flow discharge, the blockage effect of the step baffle varies and is more pronounced for the lower discharges. The computed results of the water depth are summarized in Table 6 . We note

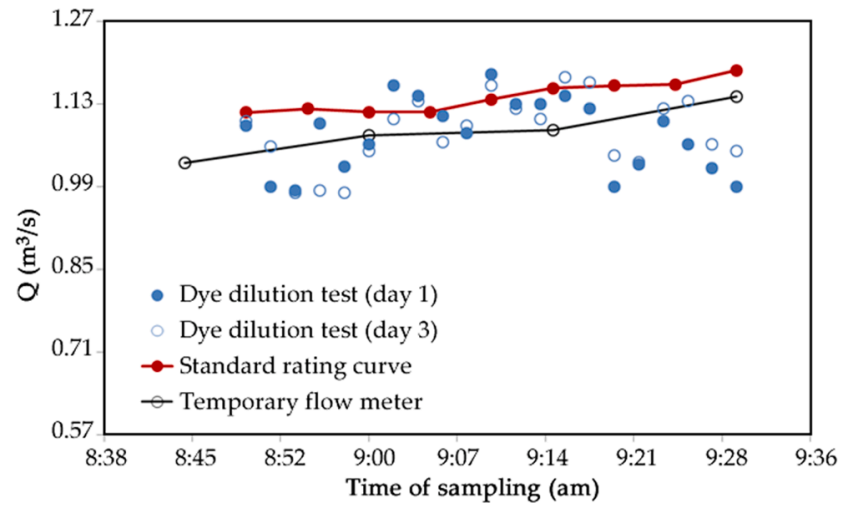

Fig. 5. Measured instantaneous flow rates (Q) in day 1 and 3 (see Table 2) using the dye dilution method (blue and hollow circles), standard rating curve (red line/circle), and temporary flow meter (black line/circle).

Table 3

Summary of the time-averaged flow rates $([\mathrm{Q}])$ measured using the dye dilution method and the standard rating curve (SRC) in Side A and B flumes.

\begin{tabular}{lllll}
\hline Test \# & Flume & SRC $[Q]\left(\mathrm{m}^{3} / \mathrm{s}\right)$ & Dye Dilution $[\mathrm{Q}]\left(\mathrm{m}^{3} / \mathrm{s}\right)$ & \% Difference \\
\hline 2 & Side B & 1.62 & 1.59 & -1.9 \\
3 & Side B & 1.15 & 1.08 & -5.7 \\
4 & Side A & 1.59 & 1.66 & +4.4 \\
5 & Side A & 1.08 & 1.15 & +6.5 \\
\hline
\end{tabular}

that the water elevation at the measurement location fluctuates because of the complex geometry of the approach channel and splitter box upstream of the Parshall flume, and as a result of water surface fluctuations. To reflect the amplitude of these fluctuations, we, in Table 6, also present the minimum and maximum levels of the water elevation for each flow discharge. The water level variation, between maximum and minimum values, represents the amplitude of the passing fluctuations over the water surface. 
Table 4

Grid sensitivity analysis using the discharge of $1.00 \mathrm{~m}^{3} / \mathrm{s}$ in the Side A flume. The Computed values of water depth for different grid systems are presented. Q $\left(\mathrm{m}^{3} / \mathrm{s}\right)$ and $\mathrm{Ha}(\mathrm{m})$ are flow discharge and flow depth, respectively. Ha, $\mathrm{Ha}_{\mathrm{min}}$, and $\mathrm{Ha}_{\max }$ represent the mean, minimum and maximum value of the water depth observed in the simulations. The standard geometry of the flume begins immediately downstream of the splitter box (Fig. 2). As seen, the simulated water depths converge to about $0.69 \mathrm{~m}$.

\begin{tabular}{llllll}
\hline $\begin{array}{l}\mathrm{Q}\left(\mathrm{m}^{3} /\right. \\
\mathrm{s})\end{array}$ & $\begin{array}{l}\text { \# Computational } \\
\text { nodes }\end{array}$ & Geometry & $\begin{array}{l}\mathrm{Ha} \\
(\mathrm{m})\end{array}$ & $\begin{array}{l}\mathrm{Ha}_{\min } \\
(\mathrm{m})\end{array}$ & $\begin{array}{l}\mathrm{Ha}_{\max } \\
(\mathrm{m})\end{array}$ \\
\hline 1.00 & $1.9 \times 10^{6}$ & Standard & 0.76 & 0.75 & 0.77 \\
1.00 & $6.5 \times 10^{6}$ & Standard & 0.69 & 0.68 & 0.70 \\
1.00 & $2.2 \times 10^{7}$ & Standard & 0.68 & 0.67 & 0.69 \\
\hline
\end{tabular}

3.4. Effect of step baffle on the amplitude of water surface fluctuations in Side B flume

A step baffle of $0.34 \mathrm{~m}$ high was installed in the Side B flume (upstream of the location of water depth measurements) to reduce the fluctuations in the water surface elevation during the water level measurements. To investigate the effect of a step baffle on reducing the water level fluctuations, a simulation within the Side B flume without step baffle was set up. In this simulation, the same flow rate $\left(=1.5 \mathrm{~m}^{3} / \mathrm{s}\right)$ and computational grid system (i.e., those that were employed to simulate the case with step baffle) (i.e., grid system with approximately 8.7 million computational grid nodes) were utilized. The grid resolution in the vertical direction is about $0.009 \mathrm{~m}$ and, thus, the height of the baffle is resolved with about 38 grid nodes. The simulation results for this case are shown in Fig. 13, where we plot the water surface geometry at two views colored with the velocity magnitude.

The level of water elevation fluctuations can be examined by plotting the water elevation in time. Fig. 14 depicts such fluctuations for the selected flow discharge of $1.5 \mathrm{~m}^{3} / \mathrm{s}$. As shown in this figure, the amplitude of the fluctuations is smaller for the case with a step baffle. The statistics of this study are also presented in Table 7, where various statistics of the water level in both cases are compared.

As seen in Table 7, the presence of a step baffle leads to smaller water surface fluctuations passing through the measurement location of the flume. It is evident from the table that the root mean square $(\mathrm{rms})$ of the water elevation fluctuation is decreased by approximately $40 \%$ owing to the presence of the step baffle. Additionally, the step baffle has led to an approximately $50 \%$ reduction in the amplitudes of the water surface fluctuations at the measurement location (see Table 7). However, as presented in this table, the mean values of the water surface elevation are almost identical in both cases.

\subsection{Comparison of the computed versus measured flow rate results}

In this section, we will compare and further validate the simulated results using the dye dilution experiment for each side of the Parshall

Table 5

Computed values of water depth for different flow discharges in the Side A flume. $\mathrm{Q}\left(\mathrm{m}^{3} / \mathrm{s}\right)$ and $\mathrm{Ha}(\mathrm{m})$ are flow discharge and flow depth, respectively. Ha, $\mathrm{Ha}_{\min }$, and $\mathrm{Ha}_{\max }$ represent the mean, minimum and maximum value of the water depth. The standard geometry of the flume begins immediately downstream of the splitter box (Fig. 2).

\begin{tabular}{llllll}
\hline $\begin{array}{l}\mathrm{Q}\left(\mathrm{m}^{3} /\right. \\
\mathrm{s})\end{array}$ & $\begin{array}{l}\text { \# Computational } \\
\text { nodes }\end{array}$ & Geometry & $\begin{array}{l}\mathrm{Ha} \\
(\mathrm{m})\end{array}$ & $\begin{array}{l}\mathrm{Ha}_{\min } \\
(\mathrm{m})\end{array}$ & $\begin{array}{l}\mathrm{Ha}_{\max } \\
(\mathrm{m})\end{array}$ \\
\hline 0.70 & $6.5 \times 10^{6}$ & Standard & 0.59 & 0.57 & 0.60 \\
1.00 & $6.5 \times 10^{6}$ & Standard & 0.69 & 0.68 & 0.70 \\
1.50 & $6.5 \times 10^{6}$ & Standard & 0.85 & 0.84 & 0.87 \\
1.00 & $2.1 \times 10^{7}$ & $\begin{array}{l}\text { With splitter } \\
\text { box }\end{array}$ & 0.68 & 0.66 & 0.69 \\
& & & & \\
\hline
\end{tabular}

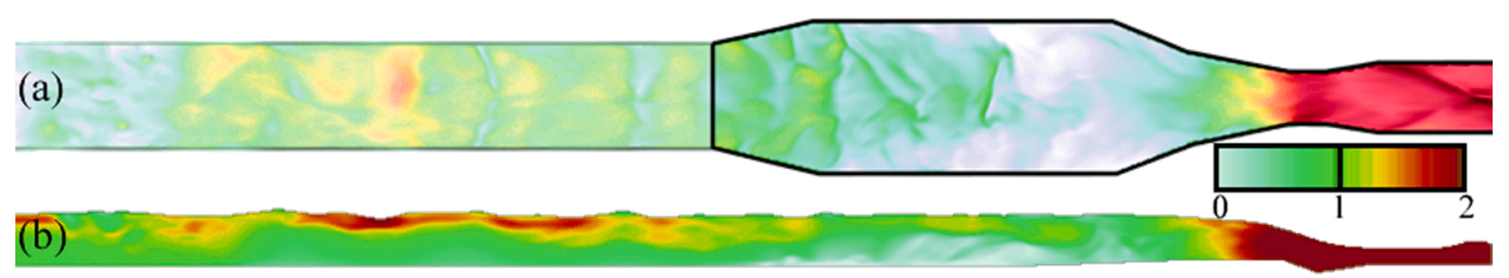

Fig. 6. Plan (a) and side (b) view of the simulated instantaneous water surface in the Side A flume. The flow discharge is equal to $1.5 \mathrm{~m}^{3} / \mathrm{s}$. The color map shows the velocity magnitude in $\mathrm{m} / \mathrm{s}$, and flow is from left to right.

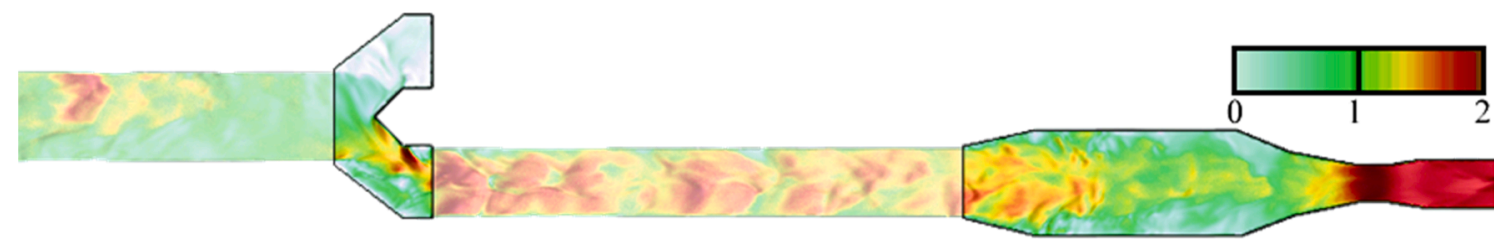

Fig. 7. Plan of the simulated instantaneous water surface in the Side A flume for the case, including the splitter. The flow discharge is equal to $1.0 \mathrm{~m}^{3} / \mathrm{s}$. The color map shows the velocity magnitude in $\mathrm{m} / \mathrm{s}$, and flow is from left to right.

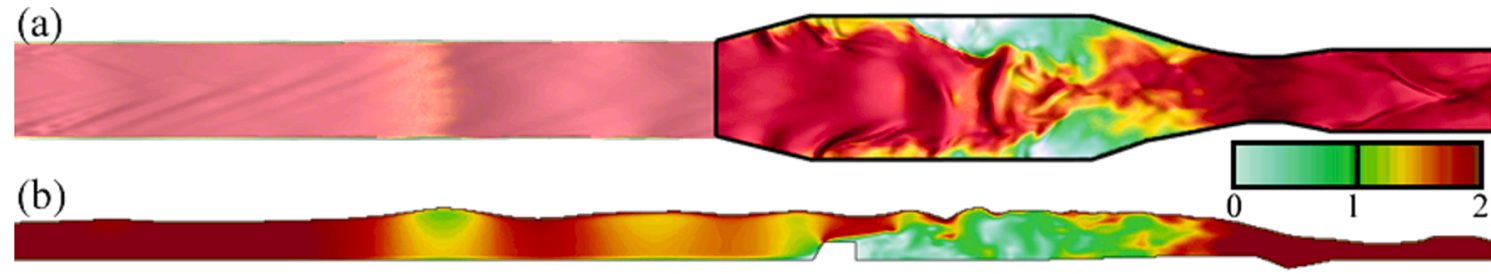

Fig. 8. Plan (a) and side (b) view of the simulated instantaneous water surface in the Side B flume with a baffle step. The flow discharge is equal to $2.0 \mathrm{~m}^{3} / \mathrm{s}$. The color map shows the velocity magnitude in $\mathrm{m} / \mathrm{s}$, and flow is from left to right. 


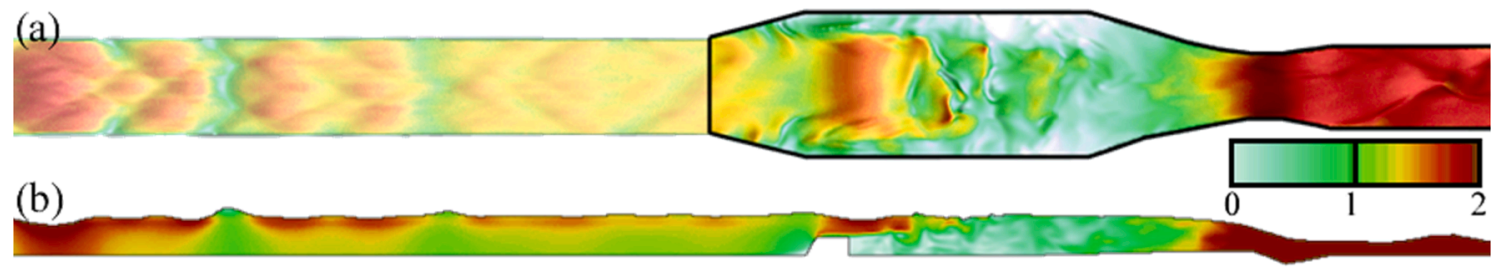

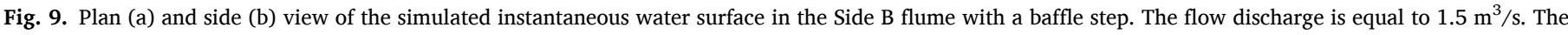
color map shows the velocity magnitude in $\mathrm{m} / \mathrm{s}$, and flow is from left to right.

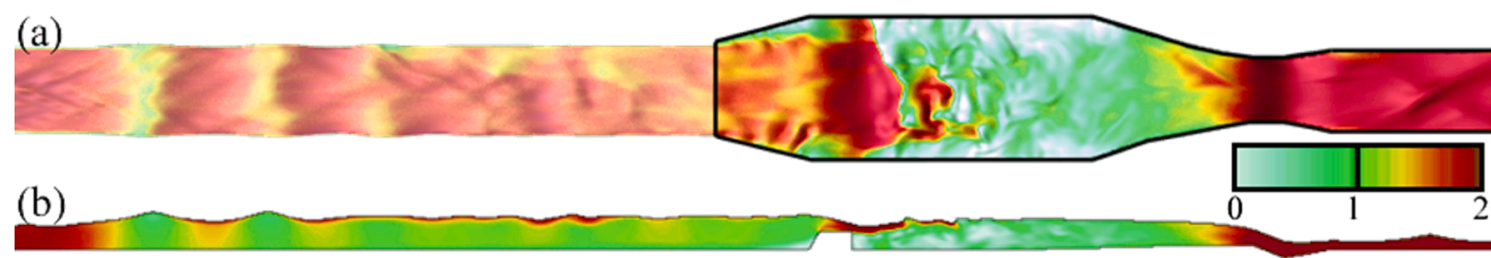

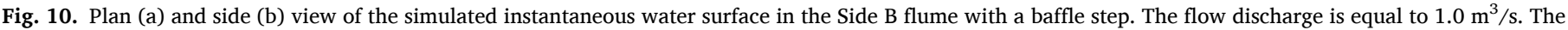
color map shows the velocity magnitude in $\mathrm{m} / \mathrm{s}$, and flow is from left to right.

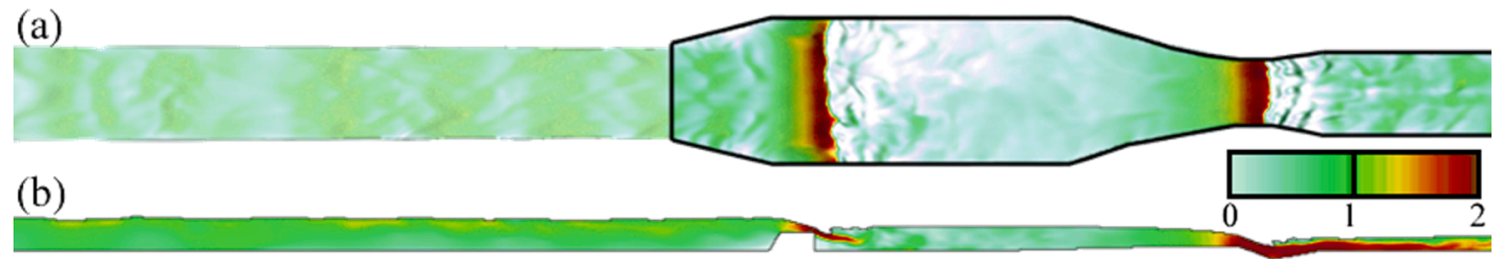

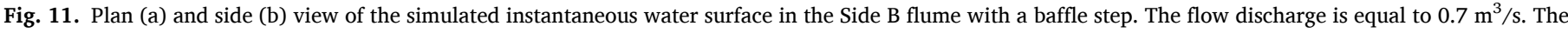
color map shows the velocity magnitude in $\mathrm{m} / \mathrm{s}$, and flow is from left to right.

(a)

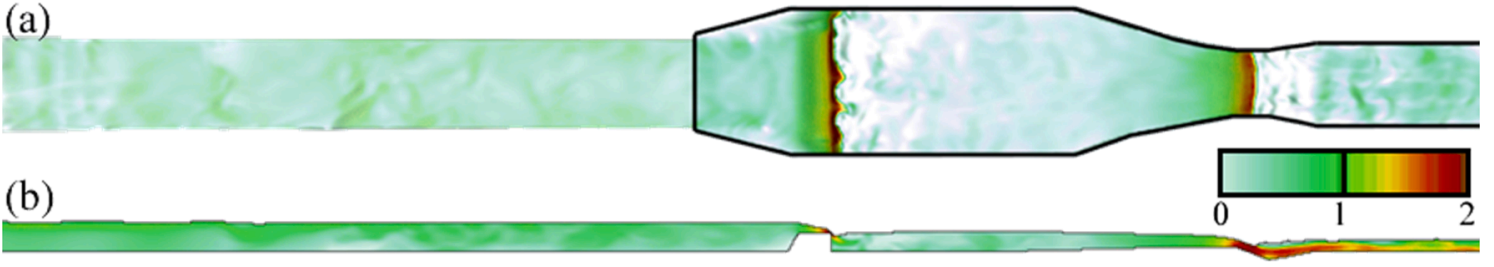

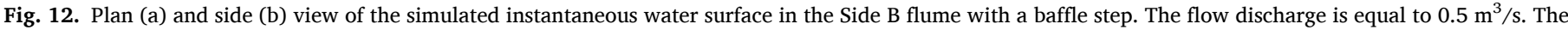
color map shows the velocity magnitude in $\mathrm{m} / \mathrm{s}$, and flow is from left to right.

\section{Table 6}

Computed values of water depth for different flow discharges for the Side B flume with step baffle. Q $\left(\mathrm{m}^{3} / \mathrm{s}\right)$ and $\mathrm{Ha}(\mathrm{m})$ are flow discharge and depth, respectively. $\mathrm{Ha}, \mathrm{Ha}_{\text {min }}$, and $\mathrm{Ha}_{\max }$ represent the mean, minimum, and maximum value of the water depth.

\begin{tabular}{llllll}
\hline $\begin{array}{l}\mathrm{Q}\left(\mathrm{m}^{3} /\right. \\
\mathrm{s})\end{array}$ & $\begin{array}{l}\text { \# Computational } \\
\text { nodes }\end{array}$ & Geometry & $\begin{array}{l}\mathrm{Ha} \\
(\mathrm{m})\end{array}$ & $\begin{array}{l}\mathrm{Ha}_{\min } \\
(\mathrm{m})\end{array}$ & $\begin{array}{l}\mathrm{Ha}_{\max } \\
(\mathrm{m})\end{array}$ \\
\hline 0.50 & $8.7 \times 10^{6}$ & Standard & 0.30 & 0.29 & 0.43 \\
0.70 & $8.7 \times 10^{6}$ & Standard & 0.41 & 0.40 & 0.42 \\
1.00 & $8.7 \times 10^{6}$ & Standard & 0.52 & 0.51 & 0.53 \\
1.50 & $8.7 \times 10^{6}$ & Standard & 0.65 & 0.64 & 0.67 \\
2.00 & $8.7 \times 10^{6}$ & Standard & 0.80 & 0.78 & 0.82 \\
\hline
\end{tabular}

flumes. Subsequently, for each side channel, a flow rate curve will be fitted to the simulated results providing a new curve for flow discharge vs. depth that is consistent with the results presented in this study. The flow rate data using the temporary flow meter are also included for comparison.

\subsubsection{Side A flume}

For this flume, the numerical simulation results for the flow rate $\mathrm{Q}$ $\left(\mathrm{m}^{3} / \mathrm{s}\right)$ versus gage depth $\mathrm{H}(\mathrm{m})$ were fitted very well $\left(\mathrm{r}^{2}=0.999\right)$ with a power-law curve, as follows:

$\mathrm{Q}=76.15 \mathrm{H}^{1.532}, \mathrm{H} Q \in(0.7,1.5)$

This may be compared to the standard rating curve for a $0.91 \mathrm{~m}$ Parshall flume (i.e., Side A flume), which reads:

$\mathrm{Q}=65.93 \mathrm{H}^{1.566}, \mathrm{H} \in(0.1,2.5)$

Comparing the flow rate curve produced by the numerical model to the dye dilution measurements, it was found that the rating curve obtained from numerical simulations matches the dye dilution measurements with mean errors of $1.6 \%$ to $2.6 \%$ (see Table 8 and Fig. 15). The flow rate values obtained from the standard rating curve are further off from both the dye dilution measurements ( $4.4 \%$ to $6.5 \%)$ and the numerical model values ( $7 \%$ to $8 \%$ ).

\subsubsection{Side B flume}

Fig. 16 depicts the simulation results of the Side B flume along with 


\section{(a)}

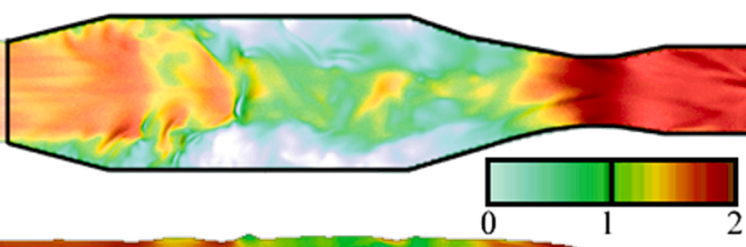

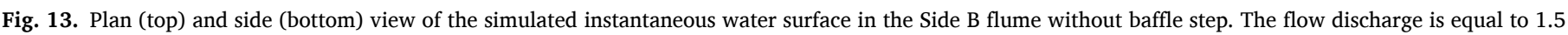
$\mathrm{m}^{3} / \mathrm{s}$. The color map shows the velocity magnitude in $\mathrm{m} / \mathrm{s}$, and flow is from left to right.

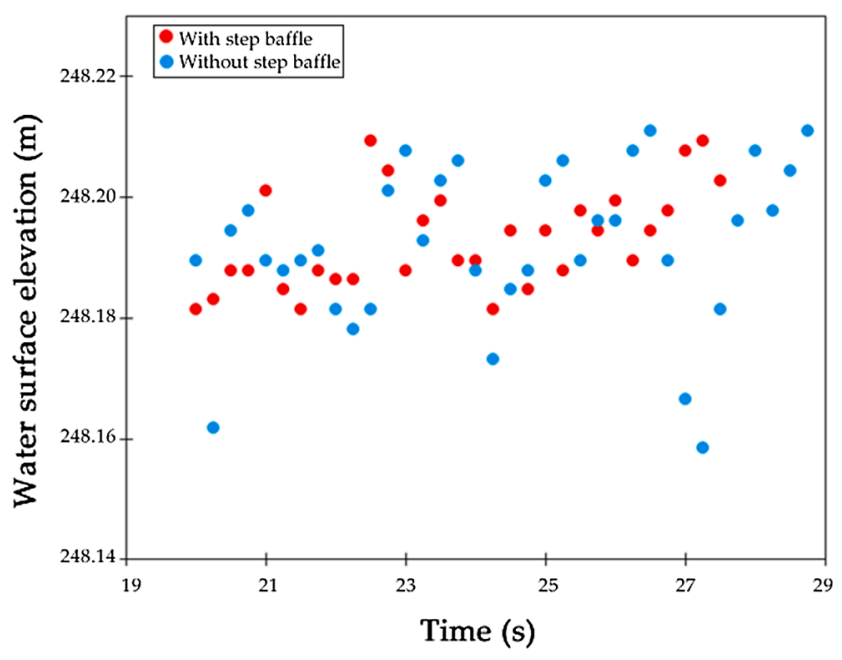

Fig. 14. Simulated water surface elevation fluctuations as a function of time in the Side B flume with and without step baffle for a flow discharge of $1.5 \mathrm{~m}^{3} / \mathrm{s}$.

Table 7

Characteristics of water surface elevation fluctuations for the Side B flume with a discharge of $1.5 \mathrm{~m}^{3} / \mathrm{s}$ for the case with and without an installed step baffle.

\begin{tabular}{lll}
\hline Water level characteristic & With baffle & Without baffle \\
\hline Mean $(\mathrm{m})$ & 248.17 & 248.18 \\
Amplitude $(\mathrm{m})$ & 0.017 & 0.032 \\
$\mathrm{rms}^{1}(\mathrm{~m})$ & 0.005 & 0.008 \\
${ }^{1}$ root mean square & & \\
\hline
\end{tabular}

the dye dilution data and standard curve values. The datasets in this figure are clustered together to enable a qualitative comparison of them around the rating curve. As seen in this figure, the dye dilution experiment results validate the simulation results of the model. The standard curve values are mainly near the lower bound of the simulation results, while the dye dilution data are closer to the upper bound of the simulation results. We note that owing to the difference between the geometry of the Side A and B flumes and standard $1.22 \mathrm{~m}$ Parshall flume, and the standard curve values are the least similar to the mean of the

Table 8

Comparison of flow rates $\left(\mathrm{m}^{3} / \mathrm{s}\right)$ in Side A flume, as measured by the standard rating curve (SRC), temporary flow meter (Tmp), dye dilution experiments (Dye), and VFS-Geophysics model simulations (model). Err Tmp-SRC, Err Dye-SRC, Err ${ }_{\text {Model-SRC, }}$ and Err Model-Dye show the percentage of the difference between the dye experiment and standard curve results, the model and standard curve results, and the model and dye experiment results, respectively.

\begin{tabular}{llllllll}
\hline $\begin{array}{l}\mathrm{Q} \\
(\mathrm{SRC})\end{array}$ & $\begin{array}{l}\mathrm{Q} \\
(\mathrm{Tmp})\end{array}$ & $\begin{array}{l}\mathrm{Q} \\
\text { (Dye) }\end{array}$ & $\begin{array}{l}\mathrm{Q} \\
\text { (Model) }\end{array}$ & $\begin{array}{l}\text { Err } \\
\text { Tmp-SRC }\end{array}$ & $\begin{array}{l}\text { Err Dye- } \\
\text { SRC }\end{array}$ & $\begin{array}{l}\text { Err } \\
\text { Model- } \\
\text { SRC }\end{array}$ & $\begin{array}{l}\text { Err } \\
\text { Model- } \\
\text { Dye }\end{array}$ \\
\hline 1.08 & 1.17 & 1.15 & 1.17 & $8.5 \%$ & $-6.5 \%$ & $8.2 \%$ & $1.6 \%$ \\
1.59 & 1.60 & 1.66 & 1.70 & $0.80 \%$ & $-4.4 \%$ & $7.2 \%$ & $2.6 \%$ \\
\hline
\end{tabular}

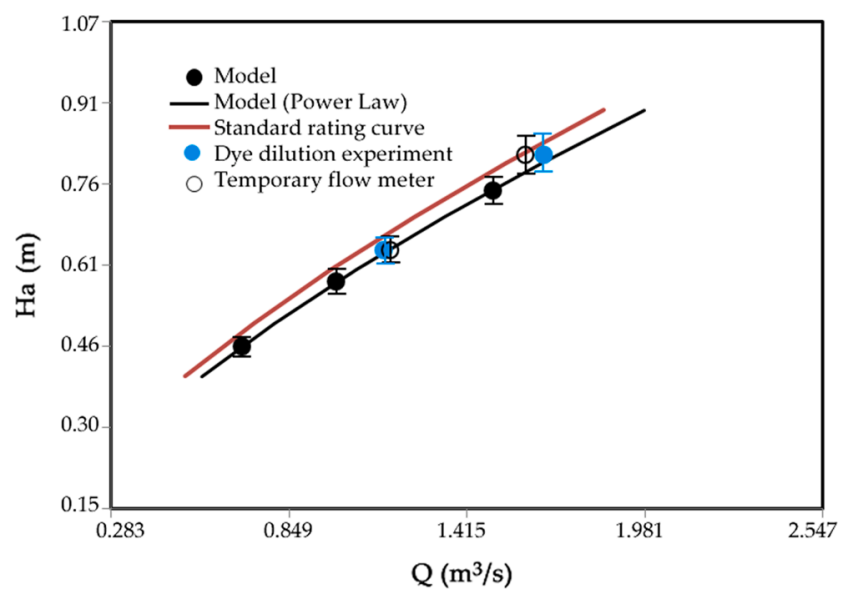

Fig. 15. Flow rate $(Q)$ curves of numerical simulated results (black solid circles), dye dilution data (blue solid circles), temporary meter data (black hollow circles), and standard curve values (red line) for the Side A flume with error bars of the flow depth Ha for the model and measurement results. The VFSGeophysical model data includes three simulated points and the power-law relationship (black line) based on those 3 points (i.e., Eq. (4)). Error bars represent $95 \%$ confidence band of the flow depth (Ha) for the model and measurement results.

simulation results. These comparisons suggest that a newly adapted rating curve developed from the mean simulated value (solid black circles in Fig. 16) can be the most reliable rating curve for the Side B flume.

By extracting a power-law rating curve, which provides the best fit,

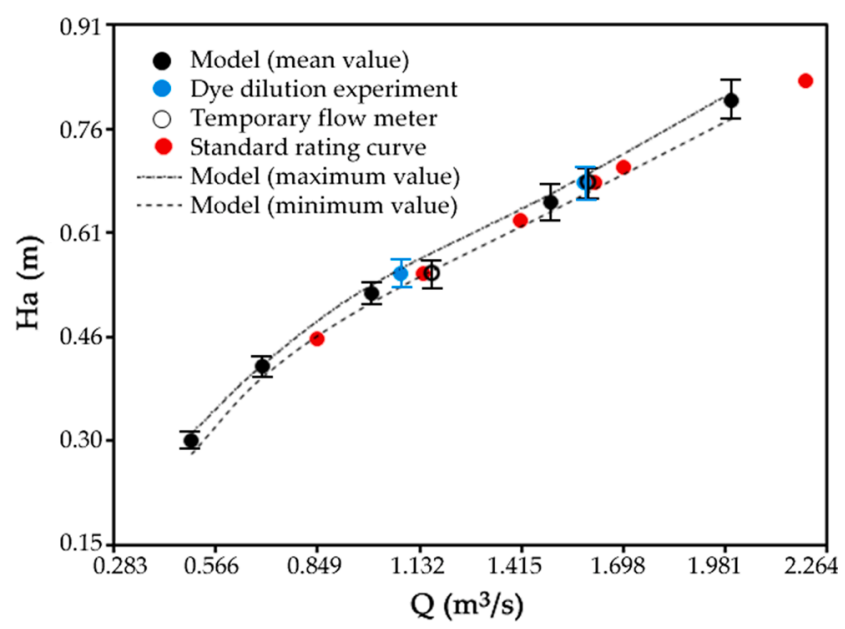

Fig. 16. Flow rate data obtained from numerical simulation results, dye dilution data, temporary flow meter, and standard curve for the Side B flume (with step baffle). Error bars, which show a 95\% confidence level, of the flow depth (Ha) are shown for the model and measurement results. 
from mean values of the numerical simulation results (solid black circles in Fig. 16), the relation between flow depth $(\mathrm{H}(\mathrm{m})$ ) and flow discharge $\left(\mathrm{Q}\left(\mathrm{m}^{3} / \mathrm{s}\right)\right)$ for the $1.22 \mathrm{~m}$ Parshall flume can be illustrated, with an $\mathrm{r}^{2}=$ 0.993, as follows:

$\mathrm{Q}=103.46 \mathrm{H}^{1.468}, \mathrm{H} \in(0.5,2.0)$

This may be compared to the standard rating curve for a standard $1.22 \mathrm{~m}$ Parshall flume:

$\mathrm{Q}=86.67 \mathrm{H}^{1.578}, H \in(0.1,3.5)$

The discrepancy between the simulated rating curve and the dye dilution measurements is within $1.3 \%$ to $2.8 \%$ (see Table 9). The correlation obtained from the standard rating curve is farther off from the dye dilution measurements (1.5-6.0\%). A third-order polynomial curve was used to overlap the numerical simulation results for the Side B flume, and the result suggests that this polynomial curve fits the numerical model's data with higher accuracy $\left(r^{2}=0.999\right)$ :

$\mathrm{Q}=-8.29 \mathrm{H}^{3}+170.21 \mathrm{H}^{2}-736.89 \mathrm{H}+1503.98$

The upper and lower bounds of the discharge (Q) in Eq. (8) are 2.0 $\mathrm{m}^{3} / \mathrm{s}$ and $0.5 \mathrm{~m}^{3} / \mathrm{s}$, respectively.

\subsection{Discussion}

A comparison of the standard rating curves, which are used by the operators of the facility, to the rating curves derived from the numerical results shows slightly different results for the $0.91 \mathrm{~m}$ and $1.22 \mathrm{~m}$ flumes (see Table 10). For the $0.91 \mathrm{~m}$ flume, the standard and numerically obtained rating curves differ by $6 \%$ to $8 \%$. If the numerical results are assumed to be $3 \%$ accurate or better, then the $8 \%$ difference in the rating curve is significant. For the $1.22 \mathrm{~m}$ flume, the standard and numerically obtained rating curves are within $3 \%$ over much of the operating range $\left(1.19-1.98 \mathrm{~m}^{3} / \mathrm{s}\right)$, but the discrepancy increases to $10 \%$ at lower flow rates.

Information is also given in Table 10 for the two flumes (Side A and B) operating in parallel, where the water level is the same in Side A and $B$. The relative errors in flow between the standard rating curve and the simulation results are also summarized in Fig. 17. Interestingly, the overall flow discrepancy is slightly lower for the case of using the Side A and B flumes in parallel compared to using Side B alone, because the standard versus numerically obtained rating curve discrepancies are opposite in sign over much of the flow range. For that reason, for the flow rates exceeding $1.132 \mathrm{~m}^{3} / \mathrm{s}$, operation of the Side A and B flumes in parallel gives flow measurement discrepancies in the range of $2-3 \%$, which is lower than those of the Side B flume operated alone. The results of uncertainty quantification in Fig. 17 suggest that operating the flumes in parallel could lead to the least error for measuring flow rates higher than $1.132 \mathrm{~m}^{3} / \mathrm{s}$. Again, we note that this is due to the opposite signs of the errors in the flow rate measurements of the Side A and B flumes and, thus, specific to the current test case.

The rating curves derived from the numerical model (Eqs. (4), 6, and 8) are valid only for the examined field metering station Parshall flumes Side A and B. In terms of the operation of the Side A and B flumes in the future, the results of this investigation and previous studies suggest that the flumes are more accurate at high flows. This suggests, then, that it is preferable to use a single flume to measure the flow rate, rather than to split the flow between the two flumes. As the $1.22 \mathrm{~m}$ flume has a larger
Table 10

Summary of water level $(\mathrm{Ha})(\mathrm{m})$ and flow rate $(\mathrm{Q})\left(\mathrm{m}^{3} / \mathrm{s}\right)$ relationships for the standard rating curve (SRC) and the VFS-Geophysics model (Model) computed rating curves, for the $0.91 \mathrm{~m}$ and $1.22 \mathrm{~m}$ wide Parshall flumes operated individually and in parallel. Diff Model - SRC $_{\text {S }} \%$ is the difference between the model and SRC values $\left(=\frac{\mathrm{Q}_{\text {Model }}-\mathrm{Q}_{\mathrm{SRC}}}{\mathrm{Q}_{\mathrm{SRC}}} \times 100\right)$.

\begin{tabular}{lccl}
\hline Ha & Q (SRC) & Q (Model) & Diff $_{\text {Model - SRC }}$ (\%) \\
\hline \multicolumn{2}{l}{$\mathbf{0 . 9 1}$ m flume (Side A) } & & \\
0.46 & 0.64 & 0.70 & 9.4 \\
0.53 & 0.82 & 0.89 & 8.8 \\
0.61 & 1.00 & 1.09 & 8.3 \\
0.69 & 1.21 & 1.30 & 7.9 \\
0.76 & 1.43 & 1.53 & 7.5 \\
0.84 & 1.65 & 1.77 & 7.2 \\
$\mathbf{1 . 2 2}$ m flume (Side B) & & \\
0.30 & 0.45 & 0.50 & 10.8 \\
0.38 & 0.65 & 0.62 & -3.8 \\
0.46 & 0.86 & 0.81 & -5.5 \\
0.56 & 1.19 & 1.16 & -2.9 \\
0.61 & 1.35 & 1.33 & -1.8 \\
0.69 & 1.63 & 1.61 & -1.3 \\
0.78 & 1.98 & 1.92 & -3.1 \\
0.84 & 2.23 & 2.10 & -5.9 \\
Side A and Side B operating in parallel & \\
0.38 & 1.13 & 1.15 & 2.1 \\
0.46 & 1.50 & 1.51 & 0.8 \\
0.56 & 2.09 & 2.13 & 2.0 \\
0.61 & 2.36 & 2.42 & 2.5 \\
0.69 & 2.84 & 2.91 & 2.6 \\
\hline
\end{tabular}

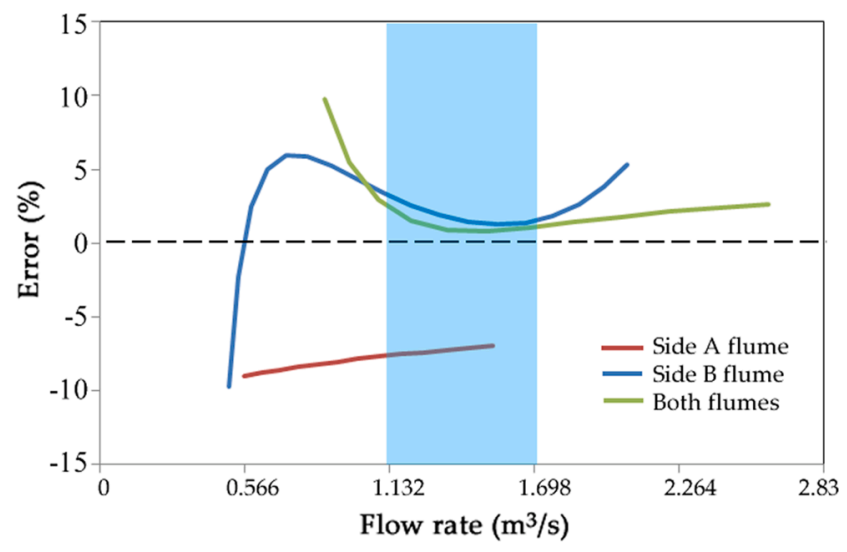

Fig. 17. Error percentage for various flow rates measured in Side A and B flumes operating individually and in parallel. Error percentage is defined as the difference between flows obtained using the standard rating curve and the rating curve obtained from numerical simulations. The blue shaded area marks the range of the studied flow rates.

capacity and was found to be closer to the standard rating curve, it is recommended that the $1.22 \mathrm{~m}$ flume be used for future flow measurements. As a general rule, and as suggested by the results of this research and previous studies, Parshall flumes are more accurate at higher flow rates. Therefore, in cases where there are more than one flume in a measuring system, it is preferable to use a single flume to measure flow rather than to split the flow between flumes.

Table 9

Comparison of flow rates $\left(\mathrm{m}^{3} / \mathrm{s}\right)$ in the Side B flume, as measured by the standard rating curve (SRC), temporary flow meter (Tmp), dye dilution experiments (Dye), and numerical simulation results (Model). Err ${ }_{T m p-S R C}, \operatorname{Err}_{\text {Dye-SRC, }} \operatorname{Err}_{\text {Model-SRC, }}$ and $\operatorname{Err}_{\text {Model-Dye }}$ show the percentage of the difference between the dye experiment and standard curve results; model and standard curve results; and model and dye experiment results, respectively.

\begin{tabular}{|c|c|c|c|c|c|c|c|}
\hline $\mathrm{Q}$ (SRC) & $\mathrm{Q}$ (Tmp) & Q (Dye) & Q (Model) & $\operatorname{Err}_{T m p-S R C}$ & $E r r_{\text {Dye-SRC }}$ & Err $_{\text {Model-SRC }}$ & Err \\
\hline 1.14 & 1.09 & 1.08 & 1.11 & $-5.5 \%$ & $-6.0 \%$ & $-3.0 \%$ & $2.8 \%$ \\
\hline 1.62 & 1.65 & 1.59 & 1.61 & $1.5 \%$ & $-1.5 \%$ & $-1.0 \%$ & $1.3 \%$ \\
\hline
\end{tabular}




\section{Conclusions}

A literature review showed that there is a long history of studies documenting the inaccuracies of standard Parshall flumes and correcting the rating curves for non-ideal installations. There are some shreds of evidence suggesting that the original standard rating curves may be inaccurate, even for well-designed installations, particularly at low flows. Dahlin and Wetzel [12] showed that, even for good inlet conditions, the observed rating curve deviated from the published curve by approximately $3 \%$ and $13 \%$ at higher (their curve reads $3 \%$ higher flow at the same depth) and lower flows (their curve reads 13\% lower flow at the same depth), respectively. The larger flume sizes (with throat width greater than $0.30 \mathrm{~m}$ ) have received little attention because very few of them are in use, and facilities that can accurately test them are few.

The temporary flow meter data does not significantly reinforce or discredit the results obtained using the VSF-Geophysics model and dye tracing. For Side A at higher flows, the temporary meter readings were close (1 to $2 \%$ ) to the standard rating curve, while at low flows, the temporary meter readings were closer to the VSF-Geophysics model results. However, the opposite of this trend was observed for Side B flume.

The VSF-Geophysics model was used to quantify the mean and fluctuating water depths in the flumes, and the corresponding mean and fluctuating water levels. Qualitatively, the numerical results show water level fluctuations similar to those observed at the site. The comparison of the Side B flume's numerical results with and without the baffle installed in the channel suggests that the installation of the step baffle reduces the water level fluctuations by approximately $40 \%$; however, there is no indication that the rating curve is affected by the baffle. As indicated in Table 7, the time-averaged water depths for the baffled and no-baffled cases are almost identical. In other words, there is no evidence that the turbulence caused by the upstream geometry is the main cause of measurement inaccuracies.

\section{Funding}

This research was funded by the Minneapolis Metropolitan Council, Office of Environmental Services, and partially supported by NSF Grant EAR-1823121.

\section{CRediT authorship contribution statement}

Ali Khosronejad: Conceptualization, Methodology, Software, Validation, Formal analysis, Investigation, Resources, Data curation, Writing - original draft, Writing - review \& editing, Visualization, Supervision, Project administration, Funding acquisition. William Herb: Conceptualization, Methodology, Validation, Formal analysis, Investigation, Resources, Data curation, Writing - original draft, Supervision, Project administration, Funding acquisition. Fotis Sotiropoulos: Conceptualization, Methodology, Software, Resources, Supervision, Project administration, Funding acquisition. Seokkoo Kang: Methodology, Software, Writing - review \& editing, Visualization. Xiaolei Yang: Methodology, Software, Writing - review \& editing, Visualization.

\section{Declaration of Competing Interest}

The authors declared that there is no conflict of interest.

\section{Acknowledgments}

The authors would like to thank Christopher Ellis and Eugene Vialrs for their technical assistance in this project and, also, the anonymous reviewers for their constructive comments, which were imperative for enhancing the quality of this paper.

\section{References}

[1] R.L. Parshall, The improved venturi flume, Trans. 89 (1926) 841-851.

[2] United States Department of the Interior, Bureau of Reclamation (USBR). Water measurement manual, 3rd ed., U.S. Government Printing Office, Washington, District of Columbia, USA, 2001.

[3] D.M. Grant, B.D. Dawson, Isco open channel flow measurement handbook, Lincoln, Nebraska, USA, 2001.

[4] Skogerboe, G. V.; Hyatt, M. L.; England, J. D.; and Johnson, J. R. Design and Calibration of Submerged Open Channel Flow Measurement Structures: Part 2 Parshall Flumes, Utah State University, Reports, Pager 81, 1967.

[5] F.W. Blaisdell, Results of Parshall flume tests, J. Irrig. Drain. Eng. 120 (2) (1994) 278-291.

[6] Chen, C. L.; Clyde, C. G.; Chu, M. S.; and Wei, C. Y. Calibration of Parshall Flumes with Non-Standard Entrance Transitions. Paper 558, Utah Water Research Laboratory, Logan, Utah, USA. 1972.

[7] B.J. Heiner, Parshall Flume Staff Gauge Location and Entrance Wing-wall Discharge Calibration Corrections, M.S. Thesis. Civil and Environmental Engineering, Utah State University, 2009.

[8] S.R. Abt, K. Thompson, K. Staker, Discharge correction for longitudinal settlement of Parshall flumes, Trans. 32 (5) (1989) 1541-1544.

[9] S.R. Abt, A. Genovez, B. Florentin, Correction for Settlement in Submerged Parshall Flumes, J. Irrig. Drain. Engrg. 120 (3) (1994) 676-682.

[10] S.J. Wright, B. Taheri, Correction to Parshall flume calibrations at low discharges, J. Irrig. Drain. Engrg. 117 (5) (1991) 800-804.

[11] S.J. Wright, B.P. Tullis, T.M. Long, Recalibration of Parshall flumes at low discharges, J. Irrig. Drain. Engrg. 120 (2) (1994) 348-362.

[12] Dahlin, W. Q. and Wetzel, J. M. Parshall Flume Calibrations Approach Studies, 12Inch Throat. St. Anthony Falls Lab, University of Minnesota, Report 279, Minneapolis, USA, 1988.

[13] R.W. Davis, S. Deutsch, A numerical-experimental study of Parshall flumes, J. Hydraul. Res. 18 (2) (1980) 135-152.

[14] B.M. Savage, B. Heiner, S.L. Barfus, Parshall flume discharge correction coefficients through modelling, Proc. ICE-Water Manage. 167 (5) (2013) 279-287.

[15] W.H. Morgan, D. Kemph, R.E. Phillips, Validation of use of dye-dilution method for flow measurement in large open and closed channel flows, National Bureau of Standards Special Publ. 484 (1977) 366-394.

[16] J. Smagorinsky, General circulation experiments with the primitive equations, Mon. Weather Rev. 91 (3) (1963) 99-164, https://doi.org/10.1175/1520-0493 (1963)091<0099:GCEWTP>2.3.CO;2.

[17] A. Khosronejad, A.M. Ghazian, D. Angelidis, E. Bagherizade, K. Flora, A. Farhadzadeh, Comparative hydrodynamic study of rigid-Lid and level-set methods for LES of open-channel flow, J. Hyd. Eng. 145 (1) (2019) 04018077 https://doi.org/10.1061/(ASCE)HY.1943-7900.0001546.

[18] S. Kang, F. Sotiropoulos, Flow phenomena and mechanisms in a field-scale experimental meandering channel with a pool-riffle sequence: Insights gained via numerical simulation, J. Geophys. Res. 116 (2011) F0301.

[19] A. Khosronejad, F. Sotiropoulos, Numerical simulation of sand waves in a turbulent open channel flow, J. of Fluid Mech. 753 (2014) 150-216.

[20] M. Sussman, E. Fatemi, An efficient, interface-preserving level set redistancing algorithm and its application to interfacial incompressible fluid flow, SIAM J. Sci. Computing 20 (4) (1999) 1165-1191.

[21] M. Sussman, E. Fatemi, P. Smereka, S. Osher, An improved level set method for incompressible two-phase flows, Comput. Fluids 27 (5-6) (1998) 663-680.

[22] A. Khosronejad, J.L. Kozarek, F. Sotiropoulos, Simulation-based approach for stream restoration structure design: model development and validation, J. Hyd. Eng. 140 (9) (2014) 04014,042, https://doi.org/10.1061/(ASCE)HY.1943 7900.0000904.

[23] A. Khosronejad, T. Le, P. DeWall, N. Bartelt, S. Woldeamlak, X. Yang, F. Sotiropoulos, High-fidelity numerical modeling of the upper mississippi river under extreme flood condition, Adv. Water Resour. 98 (2016) 97-113, https://doi. org/10.1016/j.advwatres.2016.10.018.

[24] A. Khosronejad, J.L. Kozarek, P. Diplas, C. Hill, R. Jha, P. Chatanantavet, N. Heydari, F. Sotiropoulos, Simulation-based optimization of in-stream structures design: rock vanes, Environmental Fluid Mech. 18 (3) (2018) 695-738, https://doi. org/10.1007/s10652-018-9579-7.

[25] S. Kang, F. Sotiropoulos, Numerical modeling of 3D turbulent free surface flow in natural waterways, Adv. Water Resour. 40 (2012) 23-36, https://doi.org/ 10.1016/j.advwatres.2012.01.012.

[26] A. Khosronejad, S. Kang, K. Flora, Fully coupled free-surface flow and sediment transport modelling of flash floods in a desert stream in the Mojave Desert California, Hydrological Processes 33 (2019) 2772-2791.

[27] Calderer, A., Yang, X., Angelidis, D., Khosronejad, A., Le, T., Kang, S., Gilmanov, A., Ge, L. and Borazjani, I. (2015). Virtual Flow Simulator, Version 1.0 (https:// github.com/SAFL-CFD-Lab/VFS-Rivers).

[28] D.K. Lilly, A proposed modification of the Germano subgrid-scale closure method, Phys. Fluids (1992) 633-635.

[29] S. Temeepattanapongsa, G.P. Merkley, S.L. Barfuss, B.L. Smith, Generic free-flow rating for cutthroat flumes, J. Hydraul. Engng. 139 (7) (2013) 727-1725.

[30] D. Ran, W. Wang, X. Hu, Three-dimensional numerical simulation of flow in trapezoidal cutthroat flumes based on FLOW-3D, Front. Agr. Sci. Eng. 5 (2) (2018) $168-176$.

[31] Hirt, C. W., and Williams, K. A. Flow-3D predictions for free discharge and submerged Parshall flume.” Technical Notes FSI-94-TN40, Flow Science, Inc., Santa Fe, NM, 1994. 
[32] S.D. Kim, H.L. Lee, S.D. An, Improvement of hydraulic stability for spillway using CFD model, Int. J. Phys. Sci. 5 (6) (2010) 774-780.

[33] Willeitner, R. P. Effects of submergence in Montana flumes. M.S. thesis, Dept. of Civil and Environmental Engineering, Utah State Univ., Logan, UT, 2010.
[34] B.J. Heiner, S.L. Barfuss, Parshall flume discharge corrections wall staff gauge and centerline measurements, J. Irrig. Drain. Eng. 137 (12) (2011) 779-792. 